Revista Científica de FAREM-Estelí

Medio ambiente. tecnologia y desarrollo humano

Año 10 | Núm. 37| Enero-marzo, 2021

ISSN: 2305-5790

https://rcientificaesteli.unan.edu.ni

DOI: https://doi.org/10.5377/farem.v0i37.11215

\section{Proceso de caracterización psicopedagógica en la formación inicial de docentes de la educación técnica profesional}

\section{Process of psycho-pedagogical characterization in the early formation of teachers of technical-professional education}

\section{Gloria María Surí Leyva}

Facultad de Ingeniería. Universidad de Holguín, Cuba.

gsuril@uho.edu.cu

\section{Rigoberto Pastor Sánchez Figueredo}

Facultad de Ingeniería. Universidad de Holguín, Cuba.

rigo@uho.edu.cu
RECIBIDO

$29 / 06 / 2020$

ACEPTADO

$29 / 01 / 2021$

\section{RESUMEN}

Esta investigación analiza las insuficiencias en la caracterización psicopedagógica que se realiza a los docentes en formación de la Educación Técnica Profesional, que están dadas fundamentalmente por el pobre aprovechamiento de las posibilidades que brinda el "Proceso Pedagógico Profesional", para ello y por el desconocimiento del colectivo de profesores para procesar e integrar la información obtenida a través de métodos tradicionales y las resuelve con la utilización de tareas integradoras como instrumento para desarrollar el diseño de una metodología con orientaciones generales que ofrecen precisión, objetividad y funcionalidad en sus resultados, permitiéndole al docente desde su escenario cotidiano aprovechar las potencialidades que este le ofrece sin tener que emplear "métodos y técnicas" sofisticados que no siempre están a su alcance. Con estas tareas integradoras propuestas se ofrecen posibilidades de enriquecimiento y contextualización constante para cada escenario según las necesidades y los resultados de la validación realizada con profesores guías, los posibles usuarios de la misma ofrecen evidencias positivas para su aplicación.

\section{PALABRAS CLAVE}

Caracterización psicopedagógica; educación técnica profesional. 


\section{ABSTRACT}

This research analyzes the inadequacies in the psycho-pedagogical characterization of teachers in the formation of Professional Technical Education, which are fundamentally due to the poor use of the possibilities offered by the "Professional Pedagogical Process", for this reason, and for the ignorance of the teacher's collective to process and integrate the information obtained through traditional methods and they are solved with the use of integrative task as an instrument to develop the design of a methodology with a general guideline that offers precision, objectivity, and functionality in their results, allowing the teacher to take advantage of the potentialities that this offers from their daily scenario without having to use sophisticated "methods and technique" that are not always within their reach. With these proposed integrative tasks, possibilities of enrichment and constants contextualization are offered for each scenario according to their needs and results of the validation carried out with guiding teachers, the possible user of the same offer positive evidence for its application.

\section{KEYWORDS}

Psycho-pedagogical characterization; Professional Technical Education. 


\section{INTRODUCCIÓN}

La tecnología como fenómeno social está sujeta al ser social de manera indisoluble; de acuerdo con Núñez (1999), la tecnología es movida por intereses sociales, por lo que debe ser vista como un proceso social, una práctica, que integra factores psicológicos, sociales, económicos, políticos, culturales, siempre influido por valores e intereses. Sugiere Pacey (1990) que el fenómeno de la tecnología sea estudiado y gestionado en su conjunto, como una práctica social, haciendo evidente siempre los valores culturales que le subyacen. Considera también, que en la definición más amplia de tecnología se incluyen los aspectos organizativos: actividad económica e industrial, actividad profesional, usuarios y consumidores, y los contenidos culturales: objetivos, valores, códigos éticos y códigos de comportamiento. La superación del enfoque estrictamente técnico conduce a definir que en todo cambio tecnológico es imprescindible tomar en cuenta la participación pública, las expectativas, percepciones y juicios de los no expertos quienes también participarán del proceso tecnológico.

El enfoque desde la ciencia, tecnología y sociedad (CTS) brinda una herramienta capaz de comprender a la ciencia y la tecnología como procesos vinculados directamente la sociedad.

El desarrollo de la ciencia y la tecnología ha penetrado en todos los procesos de la sociedad contemporánea. Los procesos pedagógicos no quedan al margen del impacto de las mismas, en este sentido se han realizado investigaciones dirigidas al estudio y desarrollo de diversos componentes de la personalidad.

El proceso de caracterización psicopedagógica se ha tratado de manera directa e indirecta por diferentes pedagogos y psicólogos, se puede citar a G. Torroella, A. Minujin, F. González, M. Rodríguez, I. Paz entre otros, los cuales dan relevante importancia al conocimiento por parte del profesor de las características de sus estudiantes para sobre su base realizar la orientación educativa requerida.

Teniendo en cuenta lo anterior L. Bozhovich plantea: "esta tarea dicta también un principio metódico, estudiar las leyes de la formación de la personalidad del niño en el curso del proceso pedagógico, en las condiciones reales de educación, el estudio profundo de los niños por separado". (Bozhovich, 1976, p. 59)

Con frecuencia los docentes elaboran sistemas de actividades para el trabajo educativo con su grupo sobre la base de un conocimiento pobre acerca de sus estudiantes, sin favorecer la participación activa de los mismos en la conformación de estas actividades y sin propiciar el autoconocimiento y el autorreflexión.

La caracterización psicopedagógica como proceso debe proporcionar al profesor una visión de sus estudiantes, no como entes pasivos, objetos para su exploración, sino que se cree un espacio de diálogo, de interacción 
profesor - alumno, alumno - alumno e incluso el propio alumno consigo mismo, donde se desplieguen sus operaciones cognitivas en estrecho vínculo con sus expresiones afectivas y permita el conocimiento real de todos y entre todos.

A partir de la aplicación de entrevistas, encuestas, revisión documental realizada por la investigadora, que tuvo como objetivo determinar el estado actual de los instrumentos aplicados para realizar la caracterización psicopedagógica en la formación inicial de los profesionales para la educación en la (ETP), por parte de los profesores guías y colectivos pedagógicos de las carreras, fue posible establecer una generalización de las principales insuficiencias en cuanto al carácter integrador de la caracterización psicopedagógica:

- Insuficiencias en la estructuración de la caracterización psicopedagógica que realizan los colectivos pedagógicos en la formación inicial de los docentes de la (ETP) desde una concepción integradora.

- Insuficiente conocimiento acerca de las potencialidades del proceso pedagógico profesional para la caracterización individual en la formación inicial de los docentes de la (ETP).

- Insuficiente orientación relacionada con el procesamiento de las técnicas e instrumentos que se utilizan para la caracterización psicopedagógica en la formación inicial de los docentes.

En la búsqueda de posibles soluciones a las insuficiencias antes señaladas, se pudo reconocer que resultan insuficientes las investigaciones y aportes encaminados a ofrecer pautas metodológicas sobre cómo concebir instrumentos que garanticen una caracterización psicopedagógica a partir de una concepción integradora. No se localizaron propuestas específicas sobre este particular a través de tareas integradoras.

Por todo lo anterior, se plantea como problema de investigación: Insuficiencias en la elaboración y utilización de tareas integradoras para la caracterización psicopedagógica en la formación inicial de los docentes de las carreras de la (ETP).

Este problema se manifiesta debido a las siguientes causas:

- Insuficiente preparación metodológica de los docentes para realizar el proceso de caracterización, lo que influye negativamente en su seguimiento a lo largo del curso y la carrera.

- En la realización de trabajo metodológico por parte de los profesores guías y colectivos pedagógicos para orientar y sistematizar la caracterización. 


\section{MATERIALES Y MÉTODOS}

Se precisa como objeto de investigación el proceso de caracterización psicopedagógica en la formación inicial del docente de la (ETP) y el campo de acción, las tareas integradoras para la caracterización psicopedagógica en la formación inicial del docente de la (ETP).

A partir de la determinación del problema, objeto y campo, se precisa como objetivo Diseñar una metodología que permita la caracterización psicopedagógica en la formación inicial de docentes de las carreras de la ETP a través de tareas integradoras.

\section{Preguntas científicas}

1. ¿Cuáles son los fundamentos teóricos y metodológicos que sustentan el proceso de caracterización psicopedagógica en la formación inicial del docente de la ETP a través de tareas integradoras?

2. ¿Cómo se manifiesta la caracterización psicopedagógica en la formación inicial del docente de las carreras de la ETP?

3. ¿Qué metodología favorece la caracterización psicopedagógica en la formación inicial del docente de las carreras de la ETP a través de tareas integradoras?

4. ¿Cómo elaborar tareas integradoras que permitan favorecer el proceso de caracterización psicopedagógica en la formación inicial del docente de la ETP?

5. ¿̇Cómo valorar la factibilidad de la experiencia en la aplicación práctica de las tareas integradoras propuestas?

\section{Tareas de investigación}

1. Determinar los fundamentos teóricos y metodológicos vigentes, que sustentan la elaboración de tareas integradoras para el proceso de caracterización psicopedagógica en la formación inicial del docente de la ETP.

2. Diagnosticar el estado actual que presenta la caracterización psicopedagógica en la formación inicial del docente de la ETP.

3. Diseñar una metodología que permita la caracterización psicopedagógica en la formación inicial de docentes de las carreras de la ETP a través de tareas integradoras.

4. Elaborar tareas integradoras para la caracterización psicopedagógica en la formación inicial del docente. de la ETP.

5. Valorar la factibilidad en la aplicación práctica de la metodología y las tareas integradoras propuestas para la caracterización psicopedagógica en la formación inicial de docentes de las carreras de la ETP.

En correspondencia con el objetivo y las tareas desarrolladas se emplearon los siguientes métodos de investigación: 


\section{Métodos teóricos}

- Histórico-lógico: para caracterizar la evolución que ha experimentado el proceso de caracterización psicopedagógica en la formación inicial del docente de la ETP).

- Analítico-sintético: durante todo el desarrollo del proceso de investigación, en la revisión de la bibliografía, así como en la interpretación de los resultados derivados de la aplicación de instrumentos, los cuales permitieron hacer la valoración y fundamentación del problema y asumir posiciones teóricas para sustentar la propuesta.

- Inductivo-deductivo: para realizar el análisis teórico y empírico del problema, a partir del estudio de la muestra tomada, para arribar a conclusiones y hacer generalizaciones durante todo el proceso investigativo.

\section{Métodos empíricos}

- Encuestas, entrevistas, trabajo con documentos, pre-experimento: Permitieron elaborar la fundamentación del problema con el procesamiento de los datos obtenidos a partir de su aplicación, además de servir de sustento a la propuesta generada en este trabajo. Sirvieron también para valorar la factibilidad de la propuesta.

- Métodos estadísticos matemáticos, para el cálculo porcentual en el procesamiento de la información obtenida a través de la aplicación de instrumentos y técnicas de la investigación.

\section{Población y Muestra}

La Facultad de Ciencias Técnicas de la Universidad José de la Luz y Caballero de Holguín, la integran 3 (tres) departamentos (Dptos.) docentes que constituye la población para esta investigación, de ellos se seleccionó intencionalmente el Dpto. Industrial, el mismo cuenta con 3 (tres) carreras y 4 (cuatro) grupos del curso diurno (CD); 2 (dos) grupos de la carrera de Eléctrica de 1. y 2. año; 1 (uno) de la carrera de Construcción y 1 (uno) de la carrera de Mecánica, de ellos se seleccionó de forma intencional los 4 (cuatro) grupos teniendo en cuenta que la muestra es pequeña, así mismo se procedió a la selección de 23 profesores que trabajan con los grupos de alumnos y que representa el $86,9 \%$ del total del claustro del departamento, entre los cuales se encuentran los coordinadores de año, profesores guías, jefes de carreras y profesores de experiencia.

Los resultados esperados de esta investigación, constituyen el aporte práctico y puede ser expresado de la siguiente forma:

1. Tareas Integradoras que su empleo permite la caracterización psicopedagógica en la formación inicial del docente de la (ETP).

2. Metodología para el proceso de caracterización psicopedagógica en la formación inicial del docente de la (ETP) a través de las tareas integradoras. 
La novedad de la investigación radica esencialmente en la utilización de tareas integradoras como instrumento para desarrollar el proceso de caracterización psicopedagógica en la formación inicial del docente de la (ETP).

La investigación se ha estructurado en introducción, desarrollo, conclusiones, recomendaciones, bibliografía y anexos.

\section{RESULTADOS Y DISCUSIÓN}

\section{El proceso de caracterización psicopedagógica de la personalidad en la formación inicial de docentes}

El desarrollo integral de la personalidad constituye el objetivo central de la Política Educacional Cubana. Este objetivo adquiere un énfasis particular en la formación de los profesionales de la educación, en tanto en ellos se deposita la responsabilidad de la formación y desarrollo integral de las nuevas generaciones.

Las investigaciones dirigidas al estudio y desarrollo de diversos componentes de la personalidad (motivación profesional, motivación moral, valores, autovaloración, inteligencia, etc.) aparecen abundantemente en la literatura psicológica científica, muchas de ellas referidas al contexto educativo escolar en la enseñanza primaria, media general y superior tanto en Cuba como en otros países del mundo.

El proceso de caracterización psicopedagógica se ha tratado de manera directa e indirecta por diferentes pedagogos y psicólogos, se puede citar a G. Torroella, A. Minujin, F. González, M. Rodríguez, I. Paz entre otros, los cuales dan relevante importancia al conocimiento por parte del profesor de las características de sus estudiantes para sobre su base realizar la orientación educativa requerida.

Demanera que el conocimiento del estudiante, de sus necesidades, aspiraciones dificultades, así como la concientización por el propio estudiante, teniendo en cuenta el momento del desarrollo ontogenético en que se encuentre, de sus posibilidades y limitaciones, permitirá elaborar estrategias educativas basadas en profundos conocimientos científicos que garanticen el éxito del Proceso Pedagógico Profesional. Por lo tanto, el proceso de caracterización psicopedagógica del estudiante puede resumirse de la siguiente forma:

- Es un proceso orientado a la precisión y estudio de las características más relevantes de la personalidad.

- En él participan tanto el profesor como los estudiantes.

- Permite develar lo que en materia de desarrollo se ha alcanzado hasta ese momento.

- Posibilita la estimulación de lo que aún es potencial en la personalidad. 
- Antecede necesariamente al pronóstico que sobre el comportamiento futuro del objeto se elabore.

- Apunta a la determinación de los rasgos más estables que hacen que un objeto sea él y no otro.

- Es posible orientar y encauzar el autoconocimiento y el autorreflexión.

El análisis realizado sobre la temática surge a partir de una definición general sobre caracterización abordada por A. Guétmanova (1989), al plantear que, caracterización aporta la enumeración de algunas propiedades internas y sustanciales de un hombre, fenómeno u objeto y no de su exterior como en el caso de la descripción.

De esa manera y tomando como base los elementos anteriores en el presente trabajo se asume la definición de caracterización psicopedagógica propuesta por Sánchez (2000) al plantear que:

Es un proceso que permite revelar algunas propiedades internas y sustanciales, determinando los rasgos más estables de la personalidad del educando en sus diferentes esferas y de manera integral, en el contexto pedagógico profesional, propiciando una dinámica participación de educadores y educandos y estimulando la reflexión y autorreflexión, Sánchez (2000).

Por tanto, se considera útil para esta investigación conocer la existencia de tres niveles en el conocimiento de los alumnos abordados por I. Paz (1999):

- El nivel empírico, que corresponde al conocimiento general que van adquiriendo los maestros como resultado del trato cotidiano con los escolares.

- El nivel de conocimiento científico general de los estudiantes, que utiliza técnicas específicas y proporciona una información general sobre los alumnos y los grupos.

- El nivel de estudio de casos que permite ampliar y profundizar en el conocimiento de aquellos alumnos que por sus características especiales así lo requieran.

La propuesta que se realiza en el presente trabajo se inserta en el segundo nivel, en este caso con algunas precisiones. En este nivel la caracterización psicopedagógica es responsabilidad del colectivo de profesores que trabaja con el grupo, bajo la dirección del profesor guía. Teniendo en cuenta la etapa del desarrollo ontogenético en que se encuentran los estudiantes, se emplearán el conjunto de tareas integradoras de esta investigación, para la caracterización psicopedagógica en la formación inicial de los docentes de la ETP.

Para el desarrollo del proceso de caracterización psicopedagógica, es necesario considerar varios principios: según I. Paz (1999).

- Carácter integral.

- Carácter objetivo.

- Carácter continuo. 
- Carácter explicativo.

- Carácter participativo.

- Respeto a la individualidad de la personalidad.

El primer principio puede ser explicado por la necesidad de concebir el estudio de los estudiantes en este caso no por elementos aislados de sus esferas de regulación (inductora y ejecutora), sino en su integridad.

Es preciso plantear para el análisis del segundo principio, o sea el carácter objetivo, que aun cuando se conoce que lo que se estudia es la subjetividad, este proceso debe transcurrir buscando objetivamente las expresiones del desarrollo alcanzado por la personalidad integralmente, en los diferentes contextos donde el adolescente actúa y se manifiesta.

El carácter continuo se debe garantizar mediante el seguimiento cotidiano que posibilite la búsqueda de relaciones causa - efecto en el comportamiento y el enriquecimiento de la caracterización de manera sistemática.

El carácter explicativo de este proceso se expresará en que la caracterización no sea la mera descripción del comportamiento sino la explicación bien fundamentada, que evidencie conocimiento de elementos sustanciales.

Es imposible obviar en este análisis el carácter participativo, que a su vez posibilita atender a la diversidad, ofreciendo además la posibilidad de caracterizar en esa participación el nivel de desarrollo alcanzado en la comunicación y el autoconocimiento por parte de cada alumno.

El valor de aplicación de estos principios para el desarrollo del proceso de caracterización no queda completamente explícito en la explicación anterior, sino que trasciende, si se observa este proceso como punto de partida, cimiento sobre el cual el colectivo pedagógico y el profesor guía elaborarán, ajustarán y aplicarán de conjunto, acciones que propicien el crecimiento personal en los marcos de la actividad pedagógica profesional.

La concepción de la caracterización parte de considerar que esta debe contribuir a que el educador pueda tener una información no solo de carácter general, que le permita conocer si el nivel de asimilación de sus alumnos es alto o bajo, sino que le proporcione datos más precisos que sirvan de base para organizar, orientar y dirigir su trabajo pedagógico. De esta primera consideración se derivan otras no menos importantes: una de ellas está relacionada con el tipo de prueba que se utiliza para caracterizar al estudiante en cuanto al aprendizaje, donde se deben seleccionar tareas que exploren el nivel de desarrollo de los estudiantes en áreas que están muy directamente relacionadas con los conocimientos y habilidades que han de adquirir los alumnos. 


\section{Las tareas integradoras. Algunos fundamentos teóricos y metodológicos para su elaboración}

Para analizar el proceso pedagógico profesional es necesario detenerse en un aspecto que, por su complejidad y evidencia, para algunos, en ocasiones, no se valora justamente y de ese modo, se desaprovechan sus potencialidades. Se trata de la tarea, lo que no debe reducirse al concepto estrecho de actividad que el estudiante realiza en su hogar, es decir, al deber.

La tarea es una situación de aprendizaje que provoca el profesor, dirigida a motivar la actividad de estudio independiente del estudiante para el cumplimiento de un determinado objetivo en una asignatura determinada. Según Fraga (1997) las tareas pueden ser:

- Individuales y Colectivas: Tienen que ver con la forma en que participan los estudiantes en su ejecución donde están presentes las relaciones alumnoalumno, alumno-profesor, alumno-trabajador, todos en su conjunto.

- Particulares: Están referidas a temáticas específicas dentro del contexto de una disciplina o asignatura.

- Integradoras: Se caracterizan por su carácter interdisciplinario y el comportamiento de las exigencias hacia el alumno, en la que deberá existir una asignatura responsable que constituye el eje director del nodo interdisciplinario de contenidos.

De las clasificaciones analizadas se asume en el contexto de esta investigación el criterio de Fraga (1997), citado por Borrero (2007) al proponer tareas integradoras, aspecto este al que hace referencia el estudio teórico realizado, al que se han dedicado investigadores de la psicología, la pedagogía, la sociología y la filosofía.

El proceso pedagógico profesional tiene un encargo social, deviene de la tesis marxista de que la esencia humana no es algo abstracto inherente a un individuo aislado, sino en realidad, es el conjunto de relaciones sociales, la cual es utilizada por Álvarez, (1989) para fundamentar que la relación de las actividades entre el docente y los alumnos es inmediata y fenomenológica, hay que entenderla como la manifestación concreta en las relaciones entre las generaciones.

Este criterio avala que, tanto en la enseñanza, como en el aprendizaje, se manifiesta lo social como esencia y lo individual como fenómeno, debido a que ambas actividades se realizan en función del cumplimiento de los objetivos que tienen un carácter social, donde pone de manifiesto la individualidad de la labor de cada profesor y al mismo tiempo la del estudiante.

El carácter interactivo del proceso tiene su base en los aportes de Vigotsky, (1982) al enunciar su ley de la doble formación de los procesos psíquicos superiores, según la cual, en el desarrollo cultural del niño, toda función aparece dos veces, primero a nivel social y más tarde a nivel individual, primero en el plano interpsicológico y después intrapsicológico.

Este principio exige entender de manera original el desarrollo y su vinculación con el aprendizaje, al considerar que la enseñanza va delante y conduce el 
desarrollo, aun cuando debe tener en cuenta las leyes del mismo, exige de las tareas una función educativa, de manera que en ella se aporte información que en cierta medida se tenga en cuenta el desempeño futuro del profesional en formación.

Según López, (2004), el concepto de Zona de Desarrollo Próximo (ZDP), que trasciende la descripción y valoración de lo que el alumno hace, para explorar lo que puede hacer, necesita que en la tarea se valore no solo el desarrollo actual, sino también el potencial, lo cual representa un aspecto de gran actualidad en las investigaciones sobre este tema.

El conocimiento que se requiere del estado actual del estudiante, para poder determinar y desarrollar el proceso pedagógico profesional en la Zona de Desarrollo Próximo, impone la necesidad de que la identificación de lo que sabe o puede hacer el estudiante resulte la base o punto de partida para el desarrollo futuro y para establecer las direcciones del mismo.

El carácter social del aprendizaje se refleja en dos direcciones fundamentales: en relación con los contenidos asimilados, portadores de toda la experiencia social acumulada por la humanidad y en relación con las condiciones en las que el proceso tiene lugar, el cual transcurre en un medio social, en interacción con otras personas, a través de distintas formas de colaboración y comunicación.

Por tal razón Rico, y Silvestre, (1999), afirman que las órdenes de qué hacer en las tareas adquieren un importante significado en la concepción y dirección del proceso. Estas, indicarán al estudiante un conjunto de operaciones a realizar con el conocimiento, desde su búsqueda, hasta la suficiente ejercitación, si se trata del desarrollo de una habilidad, igualmente pueden conducir al estudiante bien a la repetición mecánica o a la reflexión, profundización, suposición, búsqueda de nueva información, entre otras.

Corrales y Fariña, (1990) plantean que se trata de expresar los objetivos en término de tareas típicas que deben seleccionar al futuro egresado a través de la ejecución de determinadas acciones (habilidades) y la utilización de ciertos conceptos específicos (conocimientos), que se asimilan por su inclusión como condiciones necesarias.

Es criterio de Mariño, (1998) que la determinación de las tareas requiere de un proceso metodológico detallado donde es obligado dar los pasos necesarios y suficientes que requiere la relación objetivo - contenido en la estructuración didáctica y que se completaría con los métodos en la ejecución del proceso pedagógico profesional.

Para Álvarez, (1992) y otros constituyen la célula del proceso pedagógico porque reúnen los requisitos siguientes:

- Son el eslabón fundamental del proceso.

- Contiene la contradicción principal del proceso.

- Poseen todos los componentes y regularidades esenciales de dicho objeto. 
El fundamento de la tarea lo constituye la contradicción entre lo que se tiene y lo que el sujeto desea alcanzar. Es precisamente la contradicción, el problema planteado en la tarea lo que hace avanzar el pensamiento en el camino hacia su solución.

Las tareas docentes, según Álvarez, (1996) presentan en si misma todos los componentes del proceso, y tienen como elemento rector al objetivo.

La tarea como eslabón entre la actividad de la enseñanza del maestro y la de aprendizaje del alumno, Concepción, (1990), se convierte en la célula básica del proceso para el desarrollo de habilidades en el estudiante, Álvarez, (1996). Para esto es preciso que centre su atención en la dirección, organización y control de la actividad práctica, cognoscitiva y valorativa de los estudiantes por parte del profesor.

Las tareas se emplean óptimamente cuando se diseñan en forma de sistema, este hecho implica que cada tarea cumpla con una función específica y permita una transformación sucesiva del estudiante, es el conjunto de tareas incluidas en el sistema, el que le facilita al estudiante llegar a la esencia del fenómeno estudiado.

Las tareas promueven el carácter individualizado del proceso enseñanzaaprendizaje pues los estudiantes las resuelven de acuerdo con sus motivaciones, necesidades, experiencia previa y desarrollo intelectual y permiten la instrucción, desarrollo y educación de los sujetos por lo que su solución puede tener un carácter mediato o inmediato.

Las características mencionadas con anterioridad posibilitan que las tareas integradoras se conviertan en un instrumento ideal para la caracterización psicopedagógica del estudiante a partir de su sistematización.

Existen otras exigencias metodológicas de las tareas, relativas a su carácter variado, suficiente y diferenciado, las que se comentan a continuación al coincidir con Zilberstein y Silvestre, (2000), al plantear que las tareas deben ser:

- Variadas, en el sentido que existan actividades con diferentes niveles de exigencia que conduzcan a la aplicación del conocimiento en situaciones conocidas y no conocidas, que promuevan el esfuerzo y quehacer intelectual del escolar, conduciéndolo hacia etapas superiores de desarrollo.

- Suficientes, de modo que la propia actividad dosificada, incluya la repetición de un mismo tipo de acción en diferentes situaciones teóricas - prácticas. Las acciones a repetir son aquellas que promuevan el desarrollo de las habilidades intelectuales, la apropiación del contenido de aprendizaje, así como la formación de hábitos.

- Diferenciadas, comprende que el docente, en la concepción de la tarea, atienda las diferencias individuales de sus estudiantes, sus potencialidades, intereses, motivos. Hay estudiantes que pueden enfrentar tareas más complejas, otros aún no están en condiciones de enfrentarse, quizás, a aquellas para las que la mayoría está en condiciones. Ello implica la concepción de tareas específicas para algunos estudiantes, las que 
se utilizan en clase en la medida de que se vayan necesitando. López, (2004), citado por Borrero (2007).

Se ha demostrado que, para el desarrollo de habilidades y la independencia cognoscitiva en los educandos, es necesario que además de seleccionar las tareas dirigidas hacia ese fin, se haga con un enfoque sistémico, las mismas deben redactarse en función de responder a sus intereses, aspiraciones, expectativas, temores, lo que redundará en una mayor motivación para la resolución de determinada tarea asignada al estudiante.

En todo esto es esencial la concepción y formulación de las tareas, debido a que en ella deben concretarse qué acciones y operaciones debe realizar el alumno, vinculadas no sólo a la búsqueda y adquisición de los conocimientos y desarrollo de habilidades, sino a la formación de su personalidad, en lo que juegan un importante papel el autoconocimiento, la autovaloración de sus posibilidades y dificultades y la autorreflexión, así como el conocimiento que tiene el maestro de los alumnos.

\section{Las tareas integradoras en el proceso de caracterización psicopedagógica en la formación inicial de docentes de la ETP}

Se considera necesario que en el grupo se logre un equilibrio, respecto a los conocimientos que anteceden y se van adquiriendo por los estudiantes en el proceso pedagógico profesional. El equilibrio del grupo pudiera considerarse como uno de los indicadores cualitativos de este proceso, el cual se vincula a la caracterización inicial y sistemática, así como el vínculo de la tarea con otros indicadores cualitativos del proceso pedagógico profesional, como son el dinamismo en el desarrollo de la clase, el protagonismo del alumno, el carácter educativo de la tarea, el control y autocontrol de la misma. En la práctica pedagógica se aprecian algunas dificultades sobre el control de la tarea, tales como:

- No se controla o se controla poco.

- El control es superficial, a veces aparente y no es sistemático.

- Se controla el resultado y no el proceso de realización de la tarea.

- No se propicia que el alumno encuentre su error.

- No se aprovecha el control sobre el proceso para ofrecer niveles de ayuda.

- No se enseña y exige al alumno a realizar su autocontrol.

- El control tiende a concretarse en las exigencias instructivas de la tarea, por sobre las posibilidades desarrolladoras y educativas que esta pueda ofrecer.

Ante todo, es necesaria la individualización del trabajo educativo en el aula, debido a que los programas están elaborados, tanto por el contenido de sus tareas, como por los métodos de solución para todos los alumnos de un nivel determinado y para la realización de un proceso educativo frontal; sin embargo, ello no excluye, sino que requiere de una orientación individual de cada estudiante y de cada grupo. Debido a que el proceso de formación de la personalidad de un grupo de alumnos determinado nunca transcurre de manera equiparada o normalizada.

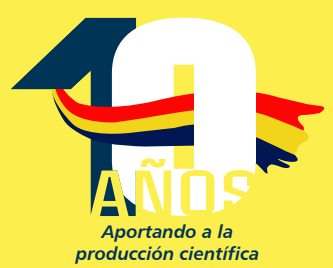


El fundamento de la tarea lo constituye la contradicción entre lo que se tiene y lo que el sujeto desea alcanzar. Es precisamente la contradicción, el problema planteado en la tarea lo que hace avanzar el pensamiento en el camino hacia su solución.

De forma tal que, en la conducción del proceso pedagógico profesional, el profesor debe saber orientar y estimular las contradicciones contenidas en la tarea para que en los estudiantes surja la necesidad de profundizar en el conocimiento tanto de sí mismos, como de vías que le permitan darle solución e investigar con más profundidad el objeto de estudio de que se trate. Es factible entonces que el proceso transcurra en la sistemática labor de resolver tareas por parte del alumno, que el profesor orientará y propiciará la posible solución de ellas de manera individual y grupal.

Contreras I. (1995) plantea que la tarea está definida por los propósitos que se persiguen en la interacción profesor - alumno y por las características particulares que dicha interacción adquiere, en términos del papel que se asigna a los participantes, profesor y estudiantes, en el logro de la meta $u$ objetivo, así como de los contenidos e instrumentos que intervienen en dicha interacción. En la definición propuesta por la autora antes mencionada, de la interpretación que se le da a la interacción profesor-alumno se han distinguido tres modelos para interpretar a la tarea y que obedecen a diferentes tendencias sobre el aprendizaje. De Zubiera (1987 y 1994), A. Merani (1969) y Davidov (1990) son:

- Modelo de transmisión pasiva.

- Escuela activa.

- Modelo de reconstrucción del conocimiento.

En el último, las tareas que se deben proponer a los alumnos durante el proceso de caracterización, tienen en cuenta de igual forma las acciones de enseñar y aprender, han de promover el desarrollo del pensamiento, las habilidades y los valores en la interacción entre el profesor y los estudiantes y propiciar de esta forma un proceso formativo.

Esta concepción del proceso es posible aplicarla a la propuesta de este trabajo, de empleo de las tareas integradoras para la caracterización psicopedagógica en la formación inicial de los profesionales de las carreras de la ETP, debido a que la tarea así concebida brinda grandes posibilidades para la interacción profesor-alumno, así como es posible aplicar las ideas de Vigotsky sobre la zona de desarrollo próximo, en la medida en que el colectivo pedagógico y el profesor guía, utilizando la tarea integradora podrá caracterizar el desarrollo alcanzado hasta ese momento del estudiante y pueda trazar sobre su base, acciones que permitan estimular la zona de desarrollo potencial, estudiando en cada caso la situación de desarrollo del momento ontogenético que se encuentre el estudiante durante su formación.

La propuesta de tareas para la caracterización psicopedagógica no posee antecedentes, sin embargo las posibilidades que ofrecen para el colectivo de profesores y la necesidad de su introducción en el proceso pedagógico profesional, forma parte del constante perfeccionamiento que se impone como un reto ante todos los que de alguna manera trabajan para la elevación 
de la calidad de dicho proceso y parte de uno de los problemas de la ETP en América Latina, de los que Cuba obviamente no está exenta y que está relacionado con la insuficiente capacitación pedagógica de los docentes.

En esta investigación se asume el término de tarea, definido por Sánchez, (2000), como el componente integrador del proceso pedagógico profesional con diferentes niveles de complejidad en que el profesor pone al estudiante a identificar, diseñar, aplicar y buscar posibles soluciones a problemas de su esfera de actuación profesional, las cuales pueden ser modeladas mediante situaciones pedagógicas en el componente académico de su contexto como estudiante.

Rasgos que la caracterizan:

- Forman parte de la estrategia que debe concebir el colectivo pedagógico y el profesor guía para caracterizar a sus alumnos.

- Permite la caracterización integral de la personalidad de los alumnos.

- Propician el cumplimiento por parte del docente de las funciones instructivas, educativas y desarrolladoras del proceso pedagógico profesional.

- Deben reflejar la unidad de lo cognitivo y lo afectivo en la personalidad.

- En ellas se da la integración de las categorías objetivos-contenidométodos.

- Permiten la interacción maestro-alumno y alumno-alumno en el proceso pedagógico profesional.

Para el planteamiento de estas tareas es importante que los profesores tengan en cuenta algunos requisitos, planteados por Toll (2003):

- La tarea para caracterizar debe plantearse ante el educando como algo motivante, de interés, que lo disponga a realizarla con satisfacción y lo mejor que él pueda. De esta manera se evita que el estudiante considere la misma como una prueba, lo que puede generar tensión e influir de manera negativa en los resultados.

- Crear un clima favorable y estimular al alumno, dándole seguridad y confianza en sus posibilidades para realizar la tarea, pero no se le brindará ayuda adicional, sino sólo lo que se plantea en las instrucciones para su aplicación.

- Se deben garantizar las condiciones del local y el número de la matrícula necesaria para facilitar la concentración del estudiante en el trabajo que realiza.

- Finalmente algo muy importante que se debe tener presente, es que los resultados sirven a la labor del profesor, por ello debe cuidarse que no sea divulgado, ni que se utilice para dar calificativos que diferencien a los alumnos.

Además de tener en cuenta los requisitos anteriormente mencionados, se hace evidente que, en la valoración del proceso de formación inicial de los profesionales para la educación en las carreras de la ETP, la caracterización se debe utilizar entre otros aspectos para conocer: 
- Los conocimientos que poseen los profesionales en formación para cumplir con las tareas asignadas de acuerdo con el año académico que cursan y los objetivos de años correspondientes.

- Lo que por experiencia práctica los profesionales en formación conocen de lo que se pretende enseñar.

- El nivel de motivación que poseen ante las tareas que deben desarrollar.

- Las necesidades básicas de aprendizaje (N. B. A.)

- Los conocimientos básicos que permiten sustentar los nuevos contenidos, ya sean aprendidos por auto-superación o trasmitidos por docentes de mayor experiencia en el intercambio que se produce como parte de su actividad práctica diaria.

- Las potencialidades reales para enfrentar las exigencias del nuevo contenido.

- Las habilidades que posee para la explotación, mantenimiento y manejo de las tecnologías existentes en el centro.

- La preparación técnica que posee para enfrentar los cambios tecnológicos y científicos que se producen continuamente.

- Los conocimientos que tiene para aplicar creadoramente los documentos legales y normativos que rigen el trabajo en la Educación Técnica y Profesional.

- Habilidades que posee para la selección de materiales para la fabricación de artículos, sobre la base de criterios económicos, tecnológicos y ambientales.

- Las potencialidades para integrar y generalizar contenidos.

- La objetividad del diseño curricular.

- Las medidas a tomar para desarrollar un proceso formativo que elimine las insuficiencias detectadas y potencie el desarrollo de los alumnos.

Los aspectos relacionados anteriormente no son los únicos a tener en cuenta, el profesor puede incluir otros que considere importantes en el desarrollo de la caracterización con el profesional en formación. Es necesario dar la oportunidad al profesional en formación para que realice una reflexión metacognitiva de su desempeño, lo que favorecerá la asunción de su estado de desarrollo y lo que necesita realizar para eliminar las insuficiencias y potenciar su desarrollo. Buscar más a fondo, "descubrir" lo que el profesional en formación conoce, cómo lo relaciona, qué puede hacer y qué puede hacer solo, no son más que las exigencias de partida para actuar en la zona de su desarrollo potencial (Vigotsky, 1982), y se revelan en la interacción directa con el educando. Posterior a la caracterización, donde el profesor obtiene de forma exitosa la información que busca, debe seguir con rigurosidad la selección de los objetivos a tratar para su cumplimiento gradual, en estrecha relación con el objetivo del año y el modelo del profesional. Se trata de seleccionar aquellos aspectos a los que es necesario darles tratamiento de una manera personalizada de acuerdo con las potencialidades de cada estudiante para propiciar el desarrollo que se desea. 


\section{Diagnóstico sobre la preparación de los docentes para la caracterización psicopedagógica en la formación inicial de docentes en la ETP}

Para determinar el estado actual de preparación que poseen los profesores para la caracterización psicopedagógica de sus estudiantes y como se trabaja en este sentido en las carreras de la ETP de la Facultad de Ciencias Técnicas se seleccionó el Dpto. Industrial, lo que constituye la población del presente trabajo.

Al realizar un muestreo se seleccionan intencionalmente a 20 profesores de los 23 que integran el claustro que trabajan con los 4 (cuatro) grupos de alumnos, para conformar así la muestra de la investigación.

Se selecciona de manera intencional para la intervención parcial al departamento industrial, donde se aplicó instrumentos a los docentes, profesores guías y jefes de carreras, así como a los directivos de los niveles organizativos, se emplea para tal fin una encuesta para profesores guías. Se entrevista a directivos del Dpto. y facultad y se realiza la revisión de documentos.

Los resultados de la indagación inicial se expresan de la siguiente forma:

- No existe en la estructura de la facultad personal capacitado para organizar y atender el trabajo de caracterización psicopedagógica de los estudiantes.

- En las actividades metodológicas realizadas a nivel de facultad y Dpto. no se le da tratamiento al tema de la caracterización psicopedagógica, se aborda solo a inicios de curso.

- El proceso de caracterización psicopedagógica no se orienta ni se ejecuta en los grupos de alumnos de manera uniforme.

- Se emplea una guía que consta de cuatro aspectos con sus indicadores (clínico, pedagógico, psicológico, socio-ambiental) cuyo resultado se traduce en la categorización de los alumnos en tres parámetros: desventajados sociales, factores de riesgo y proclives.

- Se aprecia confusión en algunos profesores guías en los indicadores de estas categorías.

- La caracterización posee de esta forma un carácter descriptivo, fenomenológico, aspecto que se constata desde el resultado teórico del instrumento aplicado.

- Se reconoce la importancia y utilidad del proceso de caracterización psicopedagógica por todos los que participan en el proceso, sin embargo recae fundamentalmente en el profesor guía, quien además no está capacitado para aprovechar las potencialidades que ofrece el proceso pedagógico profesional para ello.

- Los profesores guías no conciben que todos los que participan en el proceso pedagógico profesional deben realizar la caracterización psicopedagógica.

- La caracterización psicopedagógica es concebida como un proceso aparte, independiente del proceso pedagógico profesional.

- No se convierte en un estilo de dirección para la formación de la personalidad de los educandos.

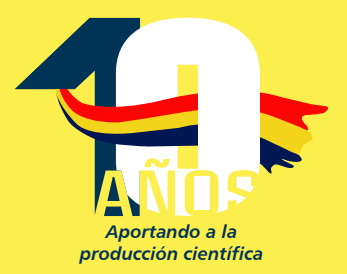


- Desconocen cómo caracterizar psicopedagógicamente a partir de las potencialidades del proceso pedagógico profesional.

- No cuentan con un sistema de indicadores que le permitan la caracterización psicopedagógica de la personalidad de los adolescentes en el proceso pedagógico profesional.

\section{Metodología para la caracterización psicopedagógica en la formación inicial de docentes de las carreras de la ETP}

El término metodología es uno de los más recurrentes en la práctica y la teoría pedagógica y se han dado varias interpretaciones sobre su significado, a partir de variadas definiciones que dependen del plano desde el cual se construyen, y utilizan. Desde el punto de vista filosófico, la metodología es vista como un recurso para el estudio de los métodos del conocimiento y transformación de la realidad. Se conciben desde un plano particular como un conjunto de métodos, procedimientos y técnicas que responden a una o varias ciencias de acuerdo con su objeto de estudio, lo que facilita el camino para llegar a un conocimiento o para cumplir los objetivos previstos. Desde este punto de vista se comparte el criterio de López (2005) citado por Borrero (2007, al plantear que una metodología es un recurso que facilita el logro de objetivos al organizar y optimizar los recursos con que cuenta el docente o investigador.

En el caso particular de esta investigación la metodología propuesta se ha estructurado a partir de los componentes siguientes:

- Objetivo general.

- Presupuestos teóricos esenciales.

- Aparato conceptual que sustenta la metodología.

- Etapas que componen la metodología.

Para ello se tomaron como referencias los trabajos publicados por Concepción (1989), Álvarez (1995), González (1999), Perera (2000), Velázquez (2000), Sánchez (2000), Toll (2004), López (2005), Andreu (2005), Lara (2006), Fernández (2006), Veitía (2006), Martínez (2011), López (2013), entre otros, en los cuales se declaran principios, se ofrecen recomendaciones y se fundamentan etapas, lo que permitió proponer una metodología estructurada en tres etapas, en la que se ofrecen recomendaciones para su concreción, lo que facilitará la comprensión por parte de los profesores.

\section{Objetivo general:}

La metodología propuesta en este trabajo tiene como objetivo la preparación de los profesores para realizar el proceso de caracterización psicopedagógica en la formación inicial de los docentes de las carreras de la ETP a través de tareas integradoras.

\section{Presupuestos teóricos esenciales:}

- Las funciones del maestro en su rol de educador trascienden el marco escolar como promotor y hacedor de cultura, tradiciones e identidad nacional y su influencia formativa en la familia y la comunidad. 
- La sociedad reclama de los profesionales de la educación educadores de nuevo tipo que preparen a sus educandos para ser competentes ante las exigencias, la dinámica y las necesidades de la vida contemporánea.

- El proceso pedagógico profesional que se diseña para la formación inicial de profesionales para la educación en las carreras de la ETP, debe tener un carácter problematizador de la teoría y la práctica pedagógica, lo que significa situar al profesional en formación ante las contradicciones propias de la actividad pedagógica que caracterizan sus diferentes contextos de actuación.

- El colectivo pedagógico que interactúa directamente en la formación inicial de los profesionales, requiere asumir el proceso pedagógico con carácter crítico y reflexivo, evaluando y cuestionando los resultados y el proceso seguido en el trabajo, buscando siempre de forma oportuna su perfeccionamiento, como un proceso continuo y necesario de la labor del maestro, involucrando con sus métodos de enseñanza una actitud reflexiva y de búsqueda de nuevos conocimientos.

- La interacción del sujeto con el objeto de trabajo en la práctica, como vía esencial para la transmisión e intercambio de ideas, vivencias y experiencias de aprendizaje, así como la práctica pedagógica dirigida a la solución de los problemas profesionales, permiten la confrontación, enriquecimiento y profundización de la teoría y la práctica.

- Para lograr una actuación profesional creadora es imprescindible dirigir el proceso pedagógico hacia el desarrollo de intereses profesionales que garanticen la calidad de la motivación profesional, el desarrollo de conocimientos y habilidades profesionales para resolver con eficiencia los problemas de la práctica pedagógica y el desarrollo de la independencia y la flexibilidad adquiridas en la actuación profesional, así como de un pensamiento reflexivo que posibilite al profesional en formación orientarse con originalidad en la solución de problemas profesionales.

- La necesidad de establecer nexos y relaciones esenciales entre las disciplinas, asignaturas que conforman el currículo de las carreras, en función de establecer relaciones significativas de enriquecimiento entre los contenidos curriculares y los aprendizajes de los participantes. Esto se alcanza como resultado del intercambio personal y los nuevos significados que asume el contenido con la interacción profesional en el marco de referencia, en el contexto de las propias acciones de trabajo que se concretan en las tareas integradoras.

- La problematización de la realidad educativa como la percepción de contradicciones esenciales en el contexto de actuación profesional pedagógica mediante la comparación de la realidad educativa con los conocimientos científicos y valores ético profesionales que tiene el sujeto, lo que conduce a la identificación de problemas pedagógicos profesionales.

- La dirección del trabajo de integración escuela-politécnica-comunidadempresa a partir de las necesidades y problemas que como política territorial se proyecten.

- Las tareas integradoras que se elaboren deben concebirse como un proyecto de solución de problemas profesionales, donde se sitúe la reflexión y la investigación de la teoría y práctica pedagógica como centro de los mismos, donde se combinen hábilmente las tareas teóricas y prácticas en un sistema que privilegie la lógica de la profesión.

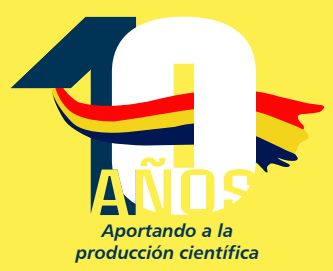




\section{Aparato conceptual que sustenta la metodología}

- Aprendizaje formativo: Se define como el proceso personológico, responsable y consciente de apropiación de la experiencia histórico social que ocurre en cooperación con el maestro y el grupo en el cual el alumno transforma la realidad y logra su crecimiento personal (R. Bermúdez, 2001).

- Crecimiento personal: El proceso de cambio y transformación que se produce en los contenidos y funciones psicológicas de la personalidad, y que permite un nivel superior de regulación y autorregulación comportamental e implica, a partir de las exigencias de la sociedad, una mejor relación con su medio, con las otras personas y consigo mismo (Bermúdez, R. y Pérez, L. 2004).

- Modo de actuación profesional pedagógica: Es el sistema de acciones pedagógicas profesionales sustentadas en conocimientos, habilidades y valores profesionales pedagógicos que permiten interactuar en la realidad educativa, percibir sus contradicciones, interpretarla y explicarla científicamente, así como transformarla creadoramente (Chirino, M 2004).

- Modo de actuación del profesional de la ETP: Se manifiesta en el cumplimiento del sistema de tareas para solucionar problemas pedagógicos, técnicos, o de los servicios en la ETP mediante la investigación científica y la utilización de las nuevas tecnologías de la información mostrando seguridad en sí mismo, exigencia, flexibilidad e independencia, motivado por la profesión, con sentido crítico, autocrítico y responsable, siendo capaz de plantearse objetivos a corto, mediano y largo plazos en su trabajo de manera que pueda enfrentar con éxito la dirección del proceso de enseñanza-aprendizaje en cualquier asignatura de las carreras de la ETP (MINED).

- Orientación: Asumida esta como el proceso de relación de ayuda que se establece entre educadores, grupos y alumnos para el desarrollo de todas las potencialidades de una persona; facilita la búsqueda de alternativas de solución de problemas o tareas, implica la utilización de métodos y técnicas de investigación y contribuye al crecimiento personal y grupal. Este concepto tiene como término esencial la relación de ayuda, que es el vínculo interpersonal donde se movilizan, en función del crecimiento personal y/o profesional, los recursos personales de un sujeto en un contexto educativo que lo facilita. Del Pino, (1998)

- Tareas integradoras: Son caracterizadas como acciones que desarrolla el profesional en formación para la solución de problemas profesionales, que requieren de la integración de objetivos, contenidos y métodos para el dominio de los modos de actuación en el objeto de la profesión contextualizado. Al analizar esta caracterización dada por (López, F 2004), se considera necesario añadir a la misma la integración de los componentes académico, laboral e investigativo, como requerimiento esencial dada las características de las tareas básicas del profesional de la educación.

- Flexibilidad: Expresada en la posibilidad de transformación, de adecuación, de enriquecimiento que posee la metodología teniendo en cuenta las características de las personas que la aplicarán y a quienes será aplicada, así como el contexto específico, en este caso la especialidad, el 
año de la carrera en que se encuentren los estudiantes, las posibilidades reales del colectivo pedagógico y del profesor guía. Sánchez, (2000).

\section{Etapas que componen la metodología}

La metodología que se propone está estructurada en tres etapas, en cada una de ellas se ofrecen recomendaciones metodológicas para su elaboración que facilitan su comprensión y utilización.

- Etapa 1: Planificación de las tareas integradoras por el profesor y/o colectivo pedagógico.

- Etapa 2: Orientación y ejecución.

- Etapa 3: Control y evaluación de las tareas orientadas.

\section{Etapa 1: Planificación de las tareas integradoras por el profesor y/o colectivo pedagógico}

La planificación de las tareas integradoras es la etapa donde el profesor y/o el colectivo pedagógico deben considerar todos los aspectos que posibiliten el enriquecimiento, la búsqueda de vías que faciliten el logro de un aprendizaje eficaz y aplicable en los estudiantes, porque se considera que es una de las etapas más importantes en la dirección del proceso pedagógico.

En la concepción y formulación de las tareas, deben concretarse qué acciones y operaciones debe realizar el profesional en formación, vinculadas no solo a la búsqueda y adquisición de los conocimientos y desarrollo de habilidades, sino a la formación de su personalidad, en lo que juegan un importante papel el auto-conocimiento, la autovaloración de sus posibilidades y dificultades y la autorreflexión.

A continuación se ofrecen algunas sugerencias que posibilitan la elaboración de las tareas integradoras para el proceso de caracterización de los estudiantes.

- Analizar y tener en cuenta el objetivo del modelo del profesional así como los objetivos del año para el cual se elaboren las tareas.

- Establecer las relaciones interdisciplinarias e ínter componentes requeridas.

- Seleccionar los contenidos integradores con los que se tiene interés de trabajar.

- Modelar el objetivo formativo de los sistemas de tareas a diseñar para caracterizar y sistematizar los contenidos.

- Elaborar los sistemas de tareas.

- Establecer los métodos y técnicas para la obtención de las informaciones que permitan valorar el nivel de desarrollo del estudiante en el cumplimiento de las tareas.

- Determinar los criterios evaluativos.

Según (López, F 2005), Las tareas integradoras que se elaboren deben cumplir determinados rasgos los cuales se asumen en la elaboración de este trabajo, ellos son los siguientes. 
- Su formulación debe ser clara y precisa, de manera que se oriente hacia las acciones y operaciones que debe desarrollar el estudiante para su cumplimiento.

- Deben provocar en el estudiante una contradicción entre lo que sabe, lo que necesita saber y los recursos que debe utilizar para su solución.

- Tienen que estar orientadas sobre la base de problemas a resolver.

- Deben requerir para su solución de la implicación reflexiva del estudiante, el intercambio con otros estudiantes y la necesidad de solicitar la ayuda requerida en determinados momentos, de manera que permitan fortalecer las relaciones afectivas entre los sujetos que intervienen en el proceso.

- En su solución se deben aplicar los contenidos recibidos y exigir la búsqueda de nuevos conocimientos.

- Deben estimular la búsqueda de alternativas de solución, la inependencia y la creatividad.

- Deben exigir la integración escuela politécnica-comunidad-empresa a partir de las necesidades y problemas del territorio.

Se considera importante recomendar en esta etapa para lograr concreción y contextualización de las tareas lo siguiente:

- Concebir las tareas integradoras a partir de los problemas profesionales.

- Elaborar tareas integradoras desde las asignaturas, disciplinas y años con vista a reforzar las habilidades profesionales, e ir dando salida desde su inicio al componente académico y el investigativo a través del componente laboral que debe desarrollar cada estudiante en los centros politécnicos.

- En la formulación de la tarea se debe lograr el vínculo entre la comunidad y la institución escolar.

- Debatir en el colectivo pedagógico los contenidos de cada asignatura que se tiene interés de evaluar en la caracterización.

- Tener en cuenta los conocimientos que poseen los estudiantes para cumplir con las tareas asignadas de acuerdo con el año académico que cursan y los objetivos de años correspondientes.

- Determinar los valores, actitudes y cualidades requeridas.

\section{Ełapa 2: Orientación y ejecución}

La orientación se asume como la relación de ayuda que se establece entre educadores, grupos y alumnos para el desarrollo todas las potencialidades de una persona. La orientación es por tanto un proceso de ayuda. Estimula las potencialidades del ser humano; facilita la búsqueda de alternativas de solución de problemas o tareas, implica la utilización de métodos y técnicas de investigación y contribuye al crecimiento personal y grupal. Este concepto tiene como término esencial la relación de ayuda, que es el vínculo interpersonal donde se movilizan, en función del crecimiento personal y/o profesional, los recursos personales de un sujeto, en un contexto educativo que lo facilita. (Del Pino, J. L.1998)

La orientación es una fase delicada, asegura el punto de partida de la realización de cualquier actividad por parte de los alumnos, puesto que esta guarda una estrecha relación con la motivación, por lo que en ningún momento se puede orientar correctamente si no se logra una motivación hacia la actividad que se desea desarrollar. 
El docente en formación en este nivel pasa de ser un receptor pasivo a ser el sujeto de un esfuerzo intelectual que demanda orientarse en la tarea, reflexionar, valorar, suponer, llegar a conclusiones, argumentar, utilizar el conocimiento, lo cual genera nuevas estrategias.

Teniendo en cuenta lo anteriormente expresado acerca de la orientación de las tareas integradoras para la caracterización, es recomendable que a la hora de realizar la misma en las carreras de la ETP, se consideren los aspectos siguientes:

- Tener en cuenta los logros y potencialidades de los estudiantes.

- Lograr una profunda motivación de los estudiantes para la realización de cualquier tarea que se le asigne, ahí radicará en gran medida el éxito de la actividad.

- Realizar ajustes necesarios de acuerdo con las condiciones existentes en el momento de orientar la tarea, debido a lo dinámico y cambiante de los problemas profesionales a los que se enfrenta el docente en formación.

- La orientación debe realizarse con claridad de forma tal que se comprenda la tarea a ejecutar y los pasos a seguir.

- Explicar a los docentes en formación las posibles alternativas a utilizar para la exposición de los resultados y los criterios a considerar para la evaluación.

Si bien, la orientación debe garantizar las transformaciones que el estudiante realice respecto al objeto del conocimiento en la ejecución de las tareas, su protagonismo en ésta también se expresa por las particularidades de su implicación en la búsqueda del conocimiento, lo que está determinado por las exigencias de las tareas. Dichas exigencias estarán dirigidas a que el estudiante obtenga la información que necesita en la medida en que simultáneamente las tareas estimulen su reflexión, la formación de generalizaciones teóricas, la revelación del valor y la formación del juicio valorativo sobre el conocimiento que se aprende, y la utilización de éste en niveles de complejidad creciente, que "tiren" del desarrollo intelectual del profesional en formación y tengan valor social, con lo cual se produce un fortalecimiento en su orientación profesional.

\section{Etapa 3: Control y evaluación de las tareas orientadas}

Existe una tendencia que está presente aún en algunos docentes a considerar a la evaluación como un momento o etapa final de una actividad de enseñanza y aprendizaje, no considerándose a la misma como proceso continuo y sistemático, lo cual pudiera estar influenciado, por una limitada comprensión de la interrelación dinámica entre los componentes del proceso de enseñanza - aprendizaje a saber: problema, objetivos, contenido, métodos, medios, forma de organización y evaluación, en su relación con el objeto de la profesión.

Al explicar cada categoría, muchos autores, enfocan a la evaluación como un eslabón final del proceso, cuya finalidad es la de comprobar el cumplimiento de los objetivos, lo que provoca que en algunos casos se considere como equivalente al examen, la medición, la comprobación, se asocie con calificación y acreditación de contenidos vencidos. Esta tendencia 
hiperboliza el papel de las notas como elemento que clasifica, sanciona o premia al estudiante, lo que ha provocado repercusión individual y social, y cuando se habla de evaluación "... a muchos de nuestros alumno, lo primero que les viene a la memoria son unos momentos difíciles y duros, en los que en un único examen se valora todo un largo proceso de trabajo, mediante una simple calificación, que en muchos casos no es el reflejo real del trabajo realizado ni de los niveles conseguidos. (Fort, R y Quin, L 1993 p. 63)

Otro extremo consiste en considerar a la evaluación como centro del proceso, sobredimensionando su alcance y subordinando a esta los demás componentes, lo que crea en los alumnos y profesores la tendencia a que se debe hacer énfasis en el proceso de enseñanza- aprendizaje a lo que se examinará, y que se debe incluir como contenido aquello que se puede medir directamente y cuantificar.

En el estudio realizado se comparte con González Pérez (2000), al considerar que la evaluación del aprendizaje tiene como características esenciales los aspectos siguientes:

- Constituye un proceso de comunicación interpersonal, donde los roles de evaluador y evaluado pueden alternarse, e incluso, darse simultáneamente.

- Tiene una determinación socio-histórica, por cuanto se realiza con referencia a normas y valores vigentes en la sociedad y las concepciones y valores de los implicados en la misma.

- Cumple diversas funciones a la vez, que son denominadas de manera diversa por los diferentes autores, siendo la formativa la esencial.

- Responde a propósitos determinados y compartidos por los participantes.

- Constituye un aspecto consustancial al proceso de aprendizaje.

- Abarca los distintos momentos del proceso del aprendizaje. Desde el estado inicial del sujeto de aprendizaje, el propio proceso en su despliegue, hasta los resultados parciales y finales correspondientes.

- Está compuesta por diversas acciones u operaciones relativas a la determinación de los objetivos, del objeto, la obtención y procesamiento de información, la elaboración de un juicio evaluativo, la retroinformación y toma de decisiones derivada del mismo, su aplicación y valoración de resultados.

- Supone diversos medios, procedimientos, fuentes y agentes de evaluación.

- Abarca atributos cualificables y cuantificables del objeto de evaluación.

- Incide sobre todos los elementos implicados en la enseñanza y ayuda a configurar el ambiente educativo.

Son diversas las definiciones de evaluación aportadas por distintos autores, diferenciándose las mismas por la extensión del concepto y la interpretación del proceso evaluativo.

Lo anterior condujo a coincidir con López, (2004) en que la evaluación es un proceso mediante el cual a partir de criterios previamente establecidos, determinados por la contextualización e interiorización de los objetivos por evaluados y evaluadores, se obtienen informaciones variadas que permiten emitir un juicio de valor integral sobre el desarrollo individual y grupal alcanzado, lo que facilita la adopción de decisiones reguladoras en un proceso comunicativo que incluye la autoevaluación y la coevaluación y 
contribuye a la autodeterminación de la personalidad. López, (2004) citado por Borrero (2007)

La evaluación debe tener un carácter predictivo, por lo que debe indicar aquello que el profesional en formación no ha logrado, pero puede lograr por la acción transformadora del proceso formativo con determinada ayuda, informando sobre las direcciones potenciales del desarrollo, lo cual es el resultado de concebir el proceso formativo desde los postulados del Enfoque Histórico Cultural, el cual aporta un marco teórico y metodológico de particular importancia, para el estudio de la evaluación.

Esta constituye una fase de verificación de la actividad realizada por el alumno en las diferentes etapas que ha recorrido, donde no puede faltar en ningún momento la estimulación en cada control y la reorientación hacia aquellos que lo necesiten.

El profesor no debe dejar de cumplir con ella, puesto que le restaría seriedad al desarrollo de la misma y provocaría la pérdida de interés por parte de sus estudiantes al no verse controlados ni estimulados por su ejecución. Además el profesor debe exigir la realización del control y la valoración del aprendizaje por parte del estudiante en la ejecución de las tareas.

Para que los estudiantes logren realizar un control valorativo de la actividad que desarrollan deben estar correctamente orientados y es aquí donde se observa la estrecha relación entre el control y las acciones de orientación.

En esta etapa se proponen algunos aspectos que se considera se tengan en cuenta en la realización de la misma:

- Cumplimentar el control a las tareas según lo planificado y la evolución de cada una de ellas, a través de un autoanálisis por parte de los profesionales en formación.

- Analizar los principales logros e insuficiencias en el cumplimiento de las tareas.

- Determinar las causas de las desviaciones y analizar los niveles de ayuda que necesite el estudiante en los controles realizados.

- Estimular los mejores resultados.

Cuando el estudiante se entrena de manera sistemática en auto controlarse, es decir realizar un control valorativo de lo que hace durante la ejecución de las tareas, va gradualmente haciendo suyo este proceder externo, o lo que es lo mismo va interiorizando el procedimiento y las exigencias hasta operar en un plano mental, con lo cual será capaz de, ante nuevas ejecuciones, obtener resultados superiores producto del nivel de autorregulación alcanzado. Estas acciones elevan el nivel de conciencia del estudiante en el proceso de enseñanza aprendizaje.

En la evaluación del nivel de desempeño de los docentes en formación, se pudieran utilizar otros criterios tales como:

- Utilización de los contenidos de las diferentes asignaturas y componentes para la determinación y solución de problemas profesionales. 
- Posibilidad de elaborar hipótesis.

- Posibilidad de transferir conocimientos, habilidades y hábitos a situaciones nuevas.

- El número y calidad de los procedimientos y productos desarrollados.

- Niveles de ayuda que necesita de acuerdo con la cantidad y complejidad de las tareas a desarrollar.

- Posibilidad de encontrar ideas nodulares.

- La motivación y nivel de pertenencia alcanzado por los profesionales en formación en la determinación y solución de problemas profesionales.

- La eficacia en la discusión, definición, distribución y valoración colectiva de las tareas.

- Defensa de sus puntos de vista y respeto a los criterios de los demás.

- La cantidad y calidad de fuentes consultadas de áreas diversas.

- Desarrollo del lenguaje y habilidades comunicativas.

- Disposición a enfrentar nuevas tareas y retos.

- Toma de decisiones ante situaciones concretas.

- Uso racional de los recursos disponibles.

- Criterios económicos, medio ambientales y culturales en general que ha tenido en cuenta para elaborar su proyecto.

- Incorporar resultados de investigaciones y experiencias de avanzadas en la práctica pedagógica.

- Aplicar los elementos de higiene escolar y las normas de protección e higiene más comunes en los procesos productivos y de servicios.

- Organizar el proceso docente - educativo de diferentes formas, desarrollar técnicas participativas y trabajos en equipos.

- Poseer atención y memoria profesional, lenguaje rico y fluido, riguroso y convincente, exigente por la calidad de su trabajo, profundidad, amplitud y pensamiento flexible.

\section{CONCLUSIONES}

- La caracterización psicopedagógica constituye necesidad y prioridad en nuestro sistema Nacional de Educación. Con esta se contribuye al perfeccionamiento del "proceso pedagógico profesional", en la medida en que se tome en consideración, que los estudiantes sean auténticos sujetos de su educación, lo que conduce al conocimiento exhaustivo como personalidad por parte del colectivo pedagógico, para guiar su evolución.

- Las insuficiencias en la caracterización psicopedagógica que se realiza a los docentes en formación de la ETP, están dadas fundamentalmente por el pobre aprovechamiento de las posibilidades que brinda el "proceso pedagógico profesional", para ello y por el desconocimiento del colectivo de profesores para procesar e integrar la información obtenida a través de métodos tradicionales.

- Existe una marcada tendencia a identificar la caracterización psicopedagógica con una "mera descripción" de algunos de los rasgos generales del estudiante y su entorno, sin llegar a la esencia interna y a las verdaderas causas que han generado su modo de actuación. 
- Las tareas integradoras, es una propuesta que ofrece posibilidades de enriquecimiento y contextualización constante para cada escenario según las necesidades.

- Las tareas integradoras propuesta para caracterizar la personalidad de los docentes en formación de la ETP, cuenta orientaciones generales que ofrecen precisión, objetividad y funcionalidad en sus resultados, permitiéndole al docente desde su escenario cotidiano aprovechar las potencialidades que este le ofrece sin tener que emplear "métodos y técnicas" sofisticados que no siempre están a su alcance.

- Los resultados de la validación realizada con profesores guías, es decir, los posibles usuarios de la misma ofrecen evidencias positivas para su aplicación.

\section{RECOMENDACIONES}

Teniendo en cuenta los resultados de la investigación realizada es posible recomendar que:

- Se continúe la investigación con la realización de un experimento pedagógico, que permita constatar la efectividad de las tareas propuesta y a la vez enriquecerla o perfeccionarla.

- Además de ser empleadas las tareas pedagógicas profesionales integradoras propuestas para la caracterización de la personalidad de los adolescentes, el profesor de la ETP puede utilizar para tal fin, tareas docentes de su propia asignatura.

- Se introduzca el conjunto de tareas pedagógicas profesionales para caracterizar la personalidad de los adolescentes de la ETP en el programa de práctica laboral para el curso regular diurno de la Facultad de Ciencias Técnicas.

- Se ofrezca un seminario de capacitación a profesores guías de la ETP para la aplicación de la metodología propuesta.

\section{BIBLIOGRAFÍA}

Álvarez, C. (1995). Epistemología de la pedagogía. Material impreso.

Álvarez, C. (1995). La escuela en la vida. Editorial San Francisco Javier Suárez, Bolivia.

Álvarez, C. (1997). La Universidad. Sus procesos y sus leyes. Curso pre-evento de pedagogía 97, palacio de las convenciones, La Habana.

Álvarez, R. (1998). Historia - Alumno - Sociedad. p.2-6. Revista Educación, No. 95, septiembre - diciembre, La Habana, Cuba.

Alonso, L. (2012). Procedimiento metodológico de diseño de la tarea integradora para evaluación del aprendizaje de los alumnos de la 
Educación Superior Pedagógica Técnica y Profesional. UCP "José de La Luz y Caballero" Holguín.

Amador, A. y otros (1995) El adolescente cubano: una aproximación al estudio de su personalidad. Editorial Pueblo y Educación, La Habana.

Bermúdez, R. y Rodríguez, M. (1996) Teoría y metodología del aprendizaje. Editorial Pueblo y Educación, La Habana.

Bozhovich, L. I. (1976) La personalidad y su formación en la edad infantil. Editorial Pueblo y Educación, La Habana.

Burke, M. T. y otros (1989) Temas de psicología pedagógica para maestros II. Editorial Pueblo y Educación, La Habana.

Burke, M. T. y otros (1995) Temas de psicología pedagógica para maestros IV. Editorial Pueblo y Educación, La Habana.

Campistrous, L. (1998) Indicadores e investigación educativa. Material impreso.

Casales, J. C. (1989) Psicología Social. Editorial de Ciencias Sociales, La Habana

Colectivo de autores (1979) Temas de psicología. Editorial Orbe, La Habana.

Colectivo de autores (1981) Pedagogía. Editorial Pueblo y Educación, La Habana.

Colectivo de autores (1992) Para la vida. Versión cubana. Editorial Pueblo y Educación, La Habana.

Colectivo de autores (1995) Investigaciones de la personalidad en Cuba. Editorial de Ciencias Sociales, La Habana.

Colectivo de autores (1996) Metodología de la investigación educacional. Primera parte. Editorial Pueblo y Educación, La Habana.

Collazo, B. y Puentes, M. (1992) La orientación en la actividad pedagógica. Editorial Pueblo y Educación, La Habana.

Concepción, R. (1989) El sistema de tareas como medio para la formación y desarrollo de los conceptos con las disoluciones en la enseñanza general media. Tesis de doctorado, Holguín.

Consuegra, J. (1988) Problemas médicos de los adolescentes. Editorial Científico Técnica, La Habana.

Contreras, I. (1995) De la enseñanza a la mediación pedagógica żcambio de nombre o cambio de paradigma, P.5 - 15. Revista educación, 19.Costa Rica.

Corona, L. A. y Fonseca, M. Aspectos didácticos acerca de las habilidades como contenido de aprendizaje. Medisur [Revista en Internet]. 2009 [Citada: 10 de noviembre de 2010]; 7(3): [aprox. 12 p.]. Disponible en: http://www.medisur.sld.cu/index.php/medisur/article/view/651/5539.

Cruz, L. y Krofchenko, O. (1995) Selección de lecturas de psicología infantil y del adolescente 1, 2, y 3 . Editorial Pueblo y Educación. La Habana.

Elliot, J. (1990) La investigación - acción en educación. Ediciones Moratas, Madrid.

Fabelo, J. R. y otros (1996) La formación de valores en las nuevas generaciones. Editorial de Ciencias Sociales, La Habana.

Fernández, M. (1994) Las tareas de la profesión de enseñar. Siglo XX. Editores S.A. España.

Freire, P. (1995) Dialogicidad y diálogo. En diálogo e interacción en el proceso pedagógico. Ediciones EL Caballito, México.

Garcés, W. (1997) El sistema de tareas como modelo de actuación didáctica en la formación de profesores de Matemática - Computación. Tesis de 
maestría, Holguín.

García, G. y Addine, F. (2005) La tarea integradora: eje integrador interdisciplinario. Seminario Nacional para Educadores. La Habana: Ministerio de Educación.

González, L. (1999) Metodología para la integración de conocimientos biológicos y metodológicos en el proceso de enseñanza aprendizaje de la metodología de la enseñanza de la Biología. Tesis de maestría, Holguín.

González, D. J. (1984) Problemas filosóficos de la psicología. Editorial Pueblo y Educación, La Habana.

González, F. y Mitjáns, A. (1989) La personalidad. Su educación y desarrollo. Editorial Pueblo y Educación. La Habana.

González, F. (1995) Comunicación, personalidad y desarrollo. Editorial pueblo y educación, La Habana.

González, F. (1997) Epistemología cualitativa y subjetividad. Editorial Pueblo y Educación, La Habana.

González, S. y otros (1997) Tareas docentes típicas en el proceso de enseñanza aprendizaje de la Física. Material docente. Instituto Superior Pedagógico "José de la Luz y Caballero", Holguín.

Guétmanova, A. (1989) Lógica. Editorial Progreso, Moscú.

Labarrere, A. (1996) Pensamiento. Análisis y autorregulación de la actividad cognoscitiva de los alumnos. Editorial Pueblo y Educación. La Habana.

Leontiev, A. (1981) Actividad conciencia personalidad. Editorial Pueblo y Educación, La Habana.

Lomov, B. (1989) El problema de la comunicación en psicología. Editorial Ciencias Sociales, La Habana.

López, J. y otros (1982) Psicología general. Editorial Pueblo y Educación, La Habana.

López, J. y otros (1987) Temas de psicología pedagógica para maestros I. Editorial Pueblo y Educación, La Habana.

López, J. y otros (1990) Temas de psicología pedagógica para maestros III. Editorial Pueblo y Educación, La Habana.

López, J. y Silverio, A. M. (1996) El diagnóstico: un instrumento de trabajo pedagógico de preescolar a escolar. Editorial Pueblo y Educación, La Habana.

Llinás, S. (1990) La formulación de los objetivos en forma de tareas. Boletín Pedagógico. I. S. P. Pinar del Río.

Majmutov, M. (1986) La enseñanza problémica. Editorial Pueblo y Educación, La Habana.

Mariño, M. (1998) Sistema de tareas pedagógicas profesionales para la asignatura Educación de la personalidad en el Instituto Superior Pedagógico de Holguín. Tesis de maestría. Holguín.

Merani, A. (1982) Diccionario de pedagogía. Ediciones Grijalbo, Barcelona. Mitjáns, A. (1995) Creatividad personalidad y educación. Editorial Pueblo

Monte, R. La actividad humana en la psicología histórico - cultural. Avances en Psicología Latinoamericana [Revista en Internet]. 2005 [Citada: 6 de julio de 2007]; 23(1): [aprox. 20 p.]. Disponible en: http://dialnet.unirioja.es/ servlet/articulo? codigo $=2741858$.

Morenza, L y otros (1995) Reflexiones en el centenario de J. Piaget y L. Vigotsky. Conferencia en video.

Morenza, L. y Terré, O. (1998) Escuela histórico - cultural. p.2-4. Revista educación, No. 93, enero - abril, La Habana, Cuba. 
Núñez, J. Pimentel, L. (1994). Problemas Sociales de la Ciencia y la Tecnología. La Habana: Editorial Félix Varela.

Núñez, J. (1999/2001/2003/2007). La Ciencia y la tecnología como procesos sociales. Lo que la educación científica no debería olvidar. La Habana: Editorial Félix Varela.

Núñez, J y Castro Díaz Valar, F (2005). Universidad, Sociedad e Innovación: Experiencias de la Universidad de la Habana, Ciencias de la administración, 7(13).

Núñez, J., L. F. Montalvo e I. Pérez (2006). La gestión del conocimiento, la información y la innovación tecnológica para el desarrollo local en: La Nueva Universidad Cubana y su contribución a la universalización del conocimiento. La Habana: Editorial Félix Varela.

Patiño, M. R. (1996) El modelo de la escuela politécnica cubana: una realidad. Editorial Pueblo y Educación, La Habana.

Paz, I. (1999) Propuesta para un enfoque personalizado en la caracterización pedagógica. Curso pre evento Pedagogía 1999, La Habana.

Peña J A, (2013). Actividades metodológicas para la preparación de facilitadores de Morfofisiología Humana en la elaboración de tareas docentes integradoras. Editorial Pueblo y Educación, La Habana.

Pérez, G. y Nocedo, I. (1989) Metodología de la investigación pedagógica y psicológica I. Editorial Pueblo y Educación, La Habana.

Pérez, G. y Nocedo, I. (1989) Metodología de la investigación pedagógica y psicológica II. Editorial Pueblo y Educación, La Habana.

Petrovki, A. (1970) Psicología General. Editorial Pueblo y Educación, La Habana.

Petrovki, A. (1979) Psicología Evolutiva y Pedagógica. Editorial Progreso, Moscú.

Pidkasisti, P. L.(1986) La actividad cognoscitiva independiente de los estudiantes en la enseñanza. Editorial Pueblo y educación, La Habana.

Ponce, J. (1981) Dialéctica de las actitudes en la personalidad. Editorial científico técnica, La Habana.

Ponce, J. (1988) El sistema psíquico del hombre. Editorial Pueblo y Educación, La Habana.

Quarti, C. (1985) El gran libro de los padres II. Ediciones Grijalbo, España.

Rico, P. (1997) Aprendizaje y reflexión en el aula. Curso pre-evento Pedagogía 97. Palacio de las convenciones, La Habana.

Rico, P. (1999) El proceso de enseñanza - aprendizaje. Material impreso.

Rodríguez, My Bermúdez, R. (1996) La personalidad del adolescente. Editorial Pueblo y Educación, La Habana.

Rodríguez, M y Bermúdez, R. (1998) Psicología del pensamiento científico. Proceso de edición.

Rubinstein, J. L (1969) Principios de psicología general. Edición Revolucionaria, La Habana.

Shorojova, E. V. y otros (1980) Problemas teóricos de la psicología de la personalidad. Editorial Orbe, La Habana.

Silvestre, M. (1993) Una concepción didáctica y técnica que estimula el desarrollo intelectual. Instituto Central de Ciencias Pedagógicas, La Habana.

Símonov, P. (1990) Motivación del cerebro. Editorial Mir, Moscú.

Stettmeier, F. y otros (1972) Psicología para maestros II. Editorial Pueblo y Educación, La Habana. 
Stettmeier, F. y otros (1973) Psicología para maestros I. Editorial Pueblo y Educación, La Habana.

Talizina, N. (1988) Psicología de la enseñanza. Editorial Progreso, Moscú.

Universidad de Duesto (1996) Metodología de la investigación cualitativa.

Material impreso, España.

\section{ANEXOS}

\section{ANEXO 1}

Prueba pedagógica para constatar el estado actual de la preparación de los profesores para la utilización de tareas integradoras desde la caracterización psicopedagógica.

Nombre y apellidos:

1. ¿QQué es la caracterización psicopedagógica?

2. ¿Cuáles son las potencialidades educativas que posee la caracterización para la formación integral del profesional de la Educación Técnica Profesional?

3. Respecto a la utilización de las tareas integradoras dentro del proceso de caracterización:

a) Señale tres elementos que fundamenten la significación que tiene para usted como docente.

b) Planifique una actividad curricular, extracurricular y laboral a realizar con su grupo donde le des tratamiento a la información que le brinda la caracterización pedagógica.

c) ¿Cómo la ejecutarías con tus estudiantes?

d) ¿Cómo la evaluarías en función del seguimiento al diagnóstico de tus estudiantes?

\section{Clave de evaluación:}

Se evalúa el resultado como Muy Favorable cuando responde correctamente más del $90 \%$ de las preguntas contenidas en el examen.

Se evalúa el resultado como Favorable cuando responde entre el 75 y el $90 \%$ de las preguntas de manera correcta.

Se evalúa de Poco Favorable cuando responde entre el 60 y el $75 \%$ de las preguntas de manera correcta.

Se evalúa Desfavorable cuanto está por debajo del 60,0\%. 


\section{ANEXO 2}

\section{Programa de Talleres Metodológicos}

\section{OBJETIVO:}

Capacitar a los profesores para la utilización de tareas integradoras desde la caracterización psicopedagógica.

\section{CONTENIDOS GENERALES:}

1. El proceso de caracterización. Fundamentos teóricos y metodológicos.

2. Tareas integradoras. Potencialidades de su uso desde la caracterización psicopedagógica.

ORGANIZACIÓN: Se aplicará este programa en la muestra de profesores del Departamento Industrial miércoles a viernes trabajando dos horas.

\section{MÉTODO PARA EL DESARROLLO DEL PROGRAMA:}

Para ello se ha concebido un sistema de talleres metodológicos, los cuales se presentan a continuación:

\section{Taller metodológico 1}

Tema: Las tareas integradoras desde la caracterización psicopedagógica de los estudiantes de carreras pedagógicas de las ramas técnicas.

Objetivo: Caracterizar los fundamentos teóricos que sustentan la aplicación de las tareas integradoras para la caracterización de los estudiantes de carreras pedagógicas de las ramas técnicas.

\section{Contenidos:}

1. La caracterización psicopedagógica en el proceso pedagógico profesional. Regularidades que lo caracterizan.

1. La utilización de tareas integradora desde la caracterización psicopedagógica. Fundamentos teóricos y metodológicos que la sustentan.

\section{Método: Trabajo por equipos.}

\section{Procedimiento:}

- Se formarán varios grupos de trabajo (según asistencia al taller).

- Se entrega un material impreso con los contendidos a tratar en el taller.

- Se entrega una hoja didáctica que contiene la siguiente actividad:

Realice una lectura del material didáctico que se entrega y mencione los rasgos esenciales de la caracterización psicopedagógica del estudiante de carreras pedagógicas de las ramas técnicas. Para ello auxíliese de las siguientes preguntas: 
a) ¿Qué es el proceso de caracterización psicopedagógica?

b) ¿Cuáles son las regularidades que lo caracterizan?

c) ¿Qué son las tareas integradoras?

d) ¿Cuáles son los fundamentos teóricos y metodológicos que la sustentan en el proceso pedagógico profesional?

e) ¿Qué significado y sentido tiene para la formación de los profesionales de la Educación Técnica Profesional desde una concepción integradora?

- Se realiza la socialización de ideas mediante el trabajo en equipo, en función de las respuestas a las preguntas de la actividad.

- Se expone por equipos las respuestas a las interrogantes planteadas.

- En plenaria se debate profesionalmente en torno a las preguntas.

- Se explica el resultado de cada una de las preguntas.

- Se aclaran dudas y corrigen errores.

- Se evalúa la preparación alcanzada por los participantes teniendo en cuenta los indicadores que se proponen más adelante.

Medios: Pizarrón, computadora, show en Power Point concebido con los contenidos a tratar en el taller, material impreso y hoja didáctica.

Evaluación: Para evaluar la preparación de los profesores en el tema se proponen los siguientes indicadores:

Muy Buena (MB): cuando responde el $85 \%$ o más de las preguntas de la actividad orientada en el taller.

Buena (B): Cuando responde de forma correcta las preguntas del instrumento en un rango comprendido desde el $70 \%$ hasta el $84 \%$.

Regular (R): Cuando responde de forma correcta las preguntas del instrumento en un rango comprendido desde el $50 \%$ hasta el $69 \%$.

Mala $(M)$ : Cuando las respuestas correctas están por debajo del $50 \%$. Taller metodológico 2.

Tema: Propuesta de tareas integradoras en el proceso de caracterización psicopedagógica.

Objetivo: Valorar la propuesta de tareas integradoras en el proceso de caracterización psicopedagógica de los estudiantes de carreras pedagógicas de las ramas técnicas.

\section{Contenidos:}

\section{Propuesta de las tareas integradoras}

Método: Trabajo por equipos.

\section{Procedimiento:}

- Se formarán varios grupos de trabajo (según asistencia al taller).

- Se entrega un material impreso que contiene las tareas integradoras propuestas.

- Se entrega una hoja didáctica que contiene la siguiente actividad:

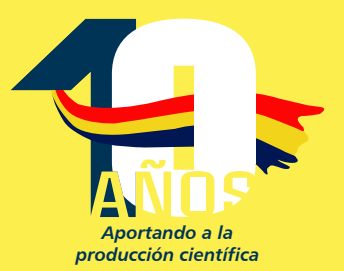


Realice una lectura del material impreso que se entrega y valore las tareas integradoras propuestas. Para ello realice las siguientes actividades:

a) ¿Considera que las tareas integradoras favorecen el proceso de caracterización de los estudiantes de carreras pedagógicas de las ramas técnicas? Argumente

b) Explicar en plenaria cada una de las tareas integradoras propuestas.

c) Diseñe una tarea docente en la asignatura que imparte en la que se le de tratamiento a los elementos detectado durante el proceso de caracterización.

- Se realiza la socialización de ideas mediante el trabajo en equipo, en función de las respuestas a las preguntas de la actividad.

- Se exponen los resultados de las preguntas.

- En plenaria se debate profesionalmente en torno a las preguntas.

Medios: Pizarrón, computadora, show en Power Point y material impreso.

Evaluación: Para evaluar la preparación de los profesores en el tema se proponen los siguientes indicadores:

Muy Buena (MB): cuando responde el $85 \%$ o más de las preguntas de la actividad orientada en el taller.

Buena (B): Cuando responde de forma correcta las preguntas del instrumento en un rango comprendido desde el $70 \%$ hasta el $84 \%$.

Regular (R): Cuando responde de forma correcta las preguntas del instrumento en un rango comprendido desde el $50 \%$ hasta el $69 \%$.

Mala (M): Cuando las respuestas correctas están por debajo del 50 